\title{
USE OF SHORT FIBERS AS A FILLER IN RUBBER COMPOUNDS
}

\author{
Natalia Meissner', Władysław M. Rzymski \\ ${ }^{1}$ Lodz University of Technology, Faculty of Material Technologies and Textile Design, Department of Material and Commodity Sciences and Textile Metrology \\ ${ }^{2}$ Lodz University of Technology, Faculty of Chemistry, Institute of Polymer and Dye Technology \\ E-mail: natalia.meissner@p.lodz.pl, wladyslaw.rzymski@p.lodz.pl
}

\begin{abstract}
:
In this work, composites made from styrene-butadiene rubber and short fibers were prepared by mixing and investigated. The influence on the vulcanization process and tensile strength properties has been studied and compared with compounds filled with carbon black. The presence of fibers gave shorter curing time and led to a slight increase in tensile strength but decreased the elongation at break of the compound.
\end{abstract}

\section{Keywords:}

Styrene-butadiene rubber (SBR), fibers, composites, reinforcement, mechanical properties.

\section{Introduction}

Styrene-butadiene rubbers (SBR) are the most commonly used synthetic rubbers today. They are produced by copolymerization of butadiene and styrene. The majority of conventional fillers used in rubber industries are silica and carbon black because of their relatively high reinforcing efficacy. Generally, a silicareinforced rubber shows a similar tensile strength to one reinforced with carbon black, but the modulus is relatively lower [1]. Currently, the necessity for reinforcing fillers from renewable resources, such as plant-based natural fibers, for the production of biosustainable composite materials is increasing in research areas and manufacturing because of their ease of processing, low cost, low density, biodegradability, and good mechanical properties. Fillers exist in a variety of systems, including biological, organic, and polymeric materials [2,3]. In polymer systems, fillers not only reduce the cost of the compound but also improve the mechanical and dynamic properties of the material. Fiber-reinforced polymer composites are now used as alternative low cost materials for structural and nonstructural applications, such as automotive applications, packaging, building products, furniture, and consumer goods. In the past, a diversity of short fibers was merged into natural rubber, and their reinforcement was discussed [4-9]. It was found that they did not provide a similar level of reinforcement compared to carbon black and silica. That is, the tensile strength and elongation at break of natural rubber based composites substantially decreased with the addition of fibers. In many cases, the loading of fibers that gave optimal fiber orientation and acceptable mechanical properties was found to be $20-30 \mathrm{phr}[5,7,8]$. Many authors have shown the effect of fiber surface modifications, using bonding agents, $\mathrm{NaOH}$ treatment, acetylation, and mercerization on the interfacial adhesion of natural fiber and rubber matrix [10-15]. The authors also analyzed the dynamic mechanical behavior of natural-fiber-reinforced rubber and curing characteristics of the compounds. They found that composite performance can be enhanced by chemically treating the fibers. Moreover, natural fibers can be added to rubber to improve or modify certain properties, such as green strength, creep resistance, hardness, aging resistance, dynamic mechanical properties, dimensional stability during fabrication, and real-time service, and to reduce the cost of fabricated articles. It is well known that blending of two or more fibers or/and fillers gives the potential for preparing new materials with specific and improved properties [16]. Recently, studies of the synergistic effects of short fibers and particulate fillers compounded with miscellaneous polymeric matrices on the physicomechanical properties of hybrid composites have been reported $[17,18]$. These studies showed promising results, in which the improvement of specific properties was observed together with additional environmental and cost benefits. Therefore, it is expected that the combined use of both short natural fibers and silica will enable one to connect the beneficial effects of individual reinforcement for the development of materials with desirable properties. In expedient applications, such as for automobile tires, the combined use of natural fibers and silica has been applied widely to improve processability, dimensional stability, and mechanical balance between abrasion resistance and rolling characteristics $[19,20]$. Tire-tread compounds containing short natural fibers together with silica are used to enhance ice traction for icy roads [21]. In this study, the primary objective was to examine the effect of the ratio of short fibers on the curing/rheological characteristic and tensile properties of styrene-butadiene rubber.

\section{Experimental}

\subsection{Materials}

KER 1500 , styrene-butadiene rubber (SBR), bound styrene content 23, $5 \%$, was obtained from Synthos S.A. (Oświęcim, Poland). Short fibers were obtained from Z. W. Biliński Sp. J. (Konstantynów Łódzki, Poland). These fibers are very short (less than $1 \mathrm{~cm}$ long). The rubber compounding ingredients, 
including zinc oxide ( $\mathrm{ZnO}$; SlovZink, a.s., Slovakia), stearic acid (AarhusKarlshamn, Sweden), sulfur (POCH, Poland), carbon black (IRB-7), $N$-tert-butyl-2-benzothiazyl sulfonamide (TBBS; Lanxess, Germany) were commercial grade.

\subsection{Preparation of the composites}

The compounding of the styrene-butadiene rubber, carbon black, fibers, and rubber additives was carried out with a laboratory two-roll mill at room temperature. The formulation of hybrid composites is given in Table 1. The rubber was first masticated on the mill, and the compounding ingredients were added in the following order: sulfur, stearic acid, fillers (carbon black or fibers), $\mathrm{ZnO}$ and TBBS. The loading ratio of fibers and carbon black was varied keeping the contents of the remaining components constant.

\subsection{RPA measurement}

The cure characteristics of the rubber compounds were measured on a Rotorless Shear Rheometer (RPA; Rubber Process Analyzer RPA2000, Alpha Technologies). The measurement was according to ASTM D 6204 at $160{ }^{\circ} \mathrm{C}$.

\section{$\underline{2.4 \text { Mooney viscosity }\left[\mathrm{ML}(1+4), 100^{\circ} \mathrm{C}\right] \text { measurement }}$}

The Mooney viscosity of the rubber compounds was measured with Mooney viscometer (Mooney MV2000, Alpha Technologies) according to the testing procedure described in ASTM D 1646. The Mooney viscosity was recorded after the sample was preheated for $1 \mathrm{~min}$ with total testing time of $4 \mathrm{~min}$. The test temperature was set at $100{ }^{\circ} \mathrm{C}$.

Table 1. Formulation of styrene-butadiene rubber composites.

\subsection{Mechanical measurement}

The tensile testing was performed on a testing machine (ZWICK Z005 TH All-round-Line) according to ASTM D 412. The dumbbell-shaped test specimens were cut from vulcanized rubbers. The specimens were stretched at room temperature $\left(25 \pm 2{ }^{\circ} \mathrm{C}\right)$. The average tensile properties for each composite were determined from five specimens. Hardness (Shore A) of the samples was also measured.

\section{Results and discussion}

\subsection{Processing properties}

The cure characteristic and Mooney viscosity [ML (1+4), $100^{\circ} \mathrm{C}$ ] of the composites were determined as a function of the fibers and the carbon black content. The results are given in Table 2. Minimum torque $\left(M_{L}\right)$ obtained from RPA testing is normally related to the viscosity of a rubber compound. The $M_{L}$ value of fiber-filled compounds was higher than that of the carbon black-filled compounds and that of the control sample. The presence of fibers increases the viscosity of the mixes. The increment in torque values with increasing filler loading indicates that as more and more filler incorporated into the rubber matrix, the mobility of the macromolecular chains of the rubber decreases resulting in more rigid vulcanizate. It is seen that the mix containing fillers provides a higher torque value indicating higher crosslinking. From Table 2 it is observed that the optimum cure time slightly decreases with the increase of fiber loading and the change in scorch time is also slight. In case of carbon black, optimum cure time and the scorch time decreases with increase of filler loading. In both cases the

\begin{tabular}{|c|c|c|c|c|c|c|c|}
\hline Ingredient & \multicolumn{7}{|c|}{ Parts per hundred rubber (phr) } \\
\hline & A & 1CB & 2CB & 3CB & 1SF & 2SF & 3SF \\
\hline SBR & 100 & 100 & 100 & 100 & 100 & 100 & 100 \\
\hline Sulfur & 1.75 & 1.75 & 1.75 & 1.75 & 1.75 & 1.75 & 1.75 \\
\hline Stearic acid & 1 & 1 & 1 & 1 & 1 & 1 & 1 \\
\hline TBBS & 1 & 1 & 1 & 1 & 1 & 1 & 1 \\
\hline ZnO & 3 & 3 & 3 & 3 & 3 & 3 & 3 \\
\hline Carbon black & - & 10 & 20 & 30 & - & - & - \\
\hline Short fibers & - & - & - & - & 10 & 20 & 30 \\
\hline
\end{tabular}

Table 2. Effect of various filler content on the cure characteristics and Mooney viscosity of styrene-butadiene rubber composites.

\begin{tabular}{|c|c|c|c|c|c|c|}
\hline Sample & $M_{L}$ & $M_{H}$ & $\mathrm{~T}_{\mathrm{s} 2}$ & $\mathrm{~T}_{\mathrm{c90}}$ & Cure rate & $M L(1+4)$ \\
\hline & (dN m) & (dN m) & (min) & (min) & $\left(\mathrm{dN} \mathrm{m} \mathrm{min} \mathrm{m}^{-1}\right)$ & $100^{\circ} \mathrm{C}$ \\
\hline$A$ & 0.60 & 7.64 & 11.3 & 19.2 & 0.18 & 34.4 \\
\hline $1 \mathrm{CB}$ & 0.71 & 9.60 & 7.0 & 14.7 & 0.32 & 38.1 \\
\hline $2 \mathrm{CB}$ & 0.97 & 12.01 & 6.0 & 12.7 & 0.36 & 43.7 \\
\hline $3 \mathrm{CB}$ & 1.29 & 14.51 & 5.2 & 11.9 & 0.61 & 50.5 \\
\hline $1 \mathrm{SF}$ & 0.93 & 10.69 & 8.7 & 16.4 & 0.31 & 39.6 \\
\hline $2 S F$ & 1.3 & 13.98 & 7.9 & 16.7 & 0.20 & 48.1 \\
\hline $3 S F$ & 1.84 & 18.71 & 7.3 & 15.1 & 0.46 & 57.6 \\
\hline
\end{tabular}


optimum cure time, as well as the scorch time, have decreased compared to the control formulation. The reason behind the increase in curing rate of the filled compounds over the control compound can be mostly attributed to the influence of $\mathrm{pH}$ of the fillers. The $\mathrm{pH}$ of carbon black is about 10 , and the $\mathrm{pH}$ of the fibers is about 9 . It is known that additives having alkaline $\mathrm{pH}$ promote vulcanization by sulfur, accelerator and accelerator activator $[22,23]$. Crosslink formation between rubber chains occurs by sequences of reactions involving sulfur, accelerator and accelerator activator, which form an active sulfurating complex [24]. The concentration effect of the curatives in the filled compounds may be an additional reason for higher curing rate of mixes. From Table 2 it is found that the optimum cure time is higher for fiber-filled composites than that for carbon black-filled composites. This is due to the fact that with increasing size of filler, incorporation and dispersion become difficult. Therefore, compounded rubbers become stiff and extent of cure value increases. The Mooney viscosity, taken as a measure of rubber compound viscosity, for the composites showed an increase with increasing both short fibers and carbon black.

\subsection{Tensile properties}

In the present study the behavior of composites containing fibers and carbon black were analyzed. The tensile properties and hardness value of rubber compounds containing various amounts of fillers are shown in Table 3. From the data in Table 3 it is seen that with an increase in the proportion of carbon black loading, the $100 \%, 200 \%$ and $300 \%$ moduli increase in the case of carbon black-rubber composites. It is known for a very long time that carbon black is enhancing the mechanical properties of rubber compounds.

The data in Table 3 show that the elongation at break increases when the carbon black loading is increased. It is known that mechanical properties of short fiber reinforced rubber composites depends on several factors such as structural aspect ratio and orientation of fibers in the final part, the degree of interfacial bonding between fiber and rubber matrices, the proper dispersion of fibers, and a balanced processability/ stiffness/ flexibility relationship for the products [25]. When the reinforced fiber composite is subjected to load, the fibers act as carriers of load and stress is transferred from matrix along the fibers leading to effective and uniform stress distribution. The uniform distribution of stress is dependent on two factors, the population and orientation of fibers. At high fiber loadings, tear strength is found to decrease as the increased strain in the matrix between closely packed fibers increases tearing and reduces the tear strength. The value of elongation at break shows a reduction with increasing fiber loading. Increased fiber loading in the rubber matrix resulted in the composite becoming stiffer and harder. This will reduce the composite's resilience and toughness and lead to lower elongation at break.

\section{Conclusions}

The obtained results show that short fibers can be used as interesting modifier of rubber blends, but for their application some specific aspects must be considered. The presence of fibers in compounds has advantageous influence on the vulcanization process and on formation of cross links in the elastomeric matrix. Therefore for the application of short fibers it is necessary to modify also the composition of the vulcanization system to ensure optimal vulcanization parameters. The nature of the elastomeric matrix must be taken in to account as well. The mechanical properties of the composites with carbon black are superior to those with fibers. Addition of short fibers (in compare with reference sample) led to slight increase of tensile strength but decreased the elongation at break of the compound. Addition of fibers also leads to increase in hardness and stiffness of the compounds. The use of silica and carbon black combined with different fiber sizes to reinforce the hybrid rubber composite will be the subject of future investigations.

\section{Acknowledgements}

Financial support for this research was provided by Synthos S.A., Oświęcim, Poland. The authors greatly appreciated the experimental support from Mr. A. Carr and Mr. P. Kwaczała at Synthos S.A.

Table 3. Tensile properties of fiber and carbon black reinforced styrene-butadiene rubber compounds.

\begin{tabular}{|c|c|c|c|c|c|c|c|}
\hline Mechanical properties & A & 1CB & 2CB & 3CB & 1WF & 2WF & 3WF \\
\hline $100 \%$ Modulus (MPa) & 0.81 & 1.04 & 1.43 & 1.9 & 1.93 & - & - \\
\hline $200 \%$ Modulus (MPa) & 1.16 & 1.71 & 3.02 & 5.0 & 2.03 & - & - \\
\hline $300 \%$ Modulus (MPa) & 1.57 & 3.03 & 6.13 & 10.1 & - & - & - \\
\hline Tensile strength (MPa) & 1.82 & 5.85 & 16.8 & 22.0 & 2.07 & 2.85 & 2.96 \\
\hline Elongation at break (\%) & 345 & 408 & 496 & 480 & 240 & 87 & 69 \\
\hline Hardness, Shore A & 40.9 & 46.2 & 51.4 & 57.0 & 55.3 & 65.2 & 75.1 \\
\hline
\end{tabular}

\section{References}

[1] Hashim A.S. et al., Silica reinforcement of epoxidized natural rubber by the sol-gel method. Journal of Sol-Gel Science and Technology, 5, 1995, 211-218.
[2] Zhang Y. et al., Effect of Carbon Black and Silica Fillers in Elastomer Blends, Macromolecules, 34, 2001, 7056-7065.

[3] Kalaprasad G.N. et al., Crab Shell Chitin Whisker Reinforced Natural Rubber Nanocomposites. 1. Processing and Swelling Behavior, Biomacromolecules, 4, 2003, 657-665. 
[4] De D. et al., The effect of grass fiber filler on curing characteristics and mechanical properties of natural rubber, Polymer for Advances Technologies, 15, 2004, 708-715.

[5] Geethamma V.G. et al., Composite of short coir fibres and natural rubber: effect of chemical modification, loading and orientation of fibre; Polymer, 39, 1998, 1483-1491.

[6] Hanafi I. et al., Oil palm wood flour reinforced epoxidized natural rubber composites: The effect of filler content and size, European Polymer Journal, 33, 1997, 1627-1632.

[7] Maya J. et al., Mechanical properties of sisal/oil palm hybrid fiber reinforced natural rubber composites, Composites Science and Technology, 64, 2004, 955-965.

[8] Lopattananon N. et al., Performance of pineapple leaf fiber-natural rubber composites: The effect of fiber surface treatments, Journal of Applied Polymer Science, 102, 2006, 1974-1984.

[9] Zhang W. et al., Mechanochemical preparation of surfaceacetylated cellulose powder to enhance mechanical properties of cellulose-filler-reinforced NR vulcanizates, Composites Science and Technology, 68, 2008, 2479-2484.

[10] Lovely M. et al., Mechanical Properties of Short-IsoraFiber-Reinforced Natural Rubber Composites: Effect of Fiber Length, Orientation, and Loading; Alkali Treatment; and Bonding Agent; Journal of Applied Polymer Science, 103, 2007, 1640-1650.

[11] Martins M.A. et al., Tire Rubber-Sisal Composites: Effect of Mercerization and Acetylation on Reinforcement, Journal of Applied Polymer Science, 89, 2003, 2507-2515.

[12] Hanafi $I$. et al, Bamboo fibre filled natural rubber composites: the effect of filler loading and bonding agent, Polymer Testing, 21, 2002, 139-144.

[13] Hanafi I. et al., The effects of a silane coupling agent on curing characteristics and mechanical properties of bamboo fibre filled natural rubber composites, European Polymer Journal, 38, 2002, 39-47.
[14]De D. et al., Curing Characteristics and Mechanical Properties of Alkali-Treated Grass-Fiber-Filled Natural Rubber Composites and Effects of Bonding Agent, Journal of Applied Polymer Science, 101, 2006, 3151-3160.

[15] Mohan T.P. et al., Chemical treatment of sisal fiber using alkali and clay method, Composites Part A, 43, 2012, 1989-1998.

[16] Mishraa S. et al., Studies on mechanical performance of biofibre/glass reinforced polyester hybrid composites, Composites Science and Technology, 63, 2003, 13771385.

[17] Haqa M. et al., Hybrid bio-based composites from blends of unsaturated polyester and soybean oil reinforced with nanoclay and natural fibers, Composites Science and Technology, 68, 2008, 3344-3351.

[18] Hudaa M.S. et al., The effect of silane treated- and untreated-talc on the mechanical and physico-mechanical properties of poly(lactic acid)/newspaper fibers/talc hybrid composites, Composites Part B: Engineering, 38, 2007, 367-379.

[19] Kikuchi N., Composition for tread rubber of tires, U.S. Patent 5852097, 1998.

[20] Takase K. Rubber composition for pneumatic tire, Japanese Patent JP2006282790, 2006.

[21] Agostini L.D. et al., Tire tread for ice traction, U.S. Patent 5967211, 1999.

[22] Schmidt A.X. et al., Principles of High Polymer Theory and Practice: Fibers, Plastics, Rubbers, Coatings, Adhesives, Mc Graw Hill, 1948.

[23] Hofmann W., Rubber Technology Handbook, Hanser Publishers, 1989.

[24] Eirich FR., Science and Technology of Rubber, Academic Press, 1978.

[25] Goettler L.A. et al., Short Fiber Reinforced Elastomers, Rubber Chemistry and Technology, 56, 1983, 619-638. 